\title{
Movimentos Sociais e Saúde: Notas para uma Discussão
}

\section{Social Movements and Health: Notes for a Debate}

\author{
Eduardo N. Stotz'
}

STOTZ, E. N. Social Movements and Health: Notes for a Debate. Cad. Saúde Públ., Rio de Faneiro, 10 (2): 264-268, Apr/fun, 1994.

This text is a contribution to the debate about the participation of social scientists in the field of health.

The difficulties and perspectives involved in the incorporation of a specific theme such as social movements are treated.

When criticizing the heavy emphasis traditionally given to "politics" in Brazilian social analysis, in reality attention is being called to the problem of the decrease in reflective power on a theoretically and politically relevant issue, the constitution of collective subjects in a specific period of time. This article represents an effort at overcoming the dilemma.

Key words: Social Movements; Public Health; Social Sciences; Political Analysis; Social

Participation

\section{O CARÁTER MARGINAL DA TEMÁTICA NA SAÚDE COLETIVA}

As lutas populares que elegeram a saúde como objeto de reivindicação podem ser situadas, em várias cidades brasileiras, desde fins da década de 70. Nesse sentido é importante assinalar que o surgimento da Famerj - Federação das Associações de Moradores do Estado do Rio de Janeiro - deu-se como um desdobramento do I Encontro Popular pela Saúde, realizado na cidade do Rio de Janeiro em 1979. Contudo, como observa Souza (1990), chama atenção, face ao dinamismo dos movimentos sociais, a situação marginal desta temática no campo da Saúde Coletiva. Esta situação contrasta com a existência de uma vasta literatura, nas Ciências Sociais, sobre $o$ assunto (Costa, 1989).

Por outro lado, a temática tem sido referida nas discussões sobre a Reforma Sanitária sem que se observe, com raras exceções (Valla \& Stotz, 1989; Costa, 1989; Souza 1990), esforços no sentido de incorporar os modos de problematizar a questão nas Ciências Sociais.

${ }^{1}$ Departamento de Ciências Sociais da Escola Nacional de Saúde Pública, Rua Leopoldo Bulhões, 1480, $9^{\circ}$ andar, Rio de Faneiro, RF, 21041-210, Brasil.
Uma explicação para esta situação de "atraso teórico" entre os protagonistas acadêmicos do movimento reformista deve considerar a forte circularidade das idéias dentro de um saber marcadamente militante. Assim, de acordo com prioridades estrategicamente definidas, alguns aspectos da realidade social foram alvo da reflexão teórica, sendo descortinados, enquanto outros permaneceram na obscuridade.

O "atraso teórico" pode ser interpretado, pois, como uma conseqüência do predomínio, no movimento reformista, de preocupações relacionadas à definição do arcabouço jurídico-legal e ao trabalho de engenharia institucional capazes de conformar um novo padrão de proteção social na saúde. A incorporação do "paradigma dos movimentos sociais" (Machado da Silva \& Ribeiro, 1985) necessariamente abriria caminho para a discussão sobre as forças sociais e seu caráter ativo na configuração da política pública.

Certamente aí fizeram-se sentir os prejuízos do viés estruturalista de leitura da obra de Marx. Vale a pena citar a seguinte avaliação de Fleury:

“... a estratégia reformista de ocupação de espaços 'estratégicos'e a quase absolutização da mudança ao nível formal da institucionalidade democrática encaminharam a Reforma Sanitária para fora das organizações sociais, acuando-as nas torres $d a$ 
academia, nos gabinetes da burocracia e nas antesalas do Parlamento. A pergunta que permanece nos debates é em que medida esta estratégia estava informada por um paradigma no qual as estruturas tomaram o lugar dos sujeitos, enfim, da própria história?”(Fleury, 1992: 10)

\section{O PROBLEMA DA CONSTITUIÇÃO DOS SUJEITOS COLETIVOS: \\ DILEMAS TEÓRICOS E DILEMAS DA PRÁTICA POLIITICA}

\section{Dilemas Teóricos}

Na tentativa de superar o esgotamento do "paradigma histórico-estrutural", quer dizer, da leitura estruturalista do marxismo, abandonouse o método mecanicista e reducionista que postula a pré-constituição dos sujeitos coletivos na conjuntura, em proveito de uma problemática propriamente política. Tal problemática não se refere mais à natureza e à historicidade do Estado enquanto forma de dominação, mas sim aos processos de produção das políticas sociais, mediada pela discussão da cidadania.

Esse legado da crítica às teses anteriores deixa-nos a impressão de um deslocamento do pêndulo na direção de um tipo de reflexão fortemente idealista: o Estado passa a ser visto como um sujeito ou um "ator" diante do qual outros sujeitos (e aqui entrariam em cena os movimentos sociais) se situam - despojados das encarnações sociais e de poder fundadas nas relações sociais de produção - para produzir a política pública.

Deste modo, a proposição de sujeitos coletivos, constituindo-se autonomamente na esfera do político, desconsidera, mais uma vez, a rica história da literatura sobre os movimentos sociais no Brasil; desconhece, pelo "politicismo" da reflexão teórica, aquilo que constituiu a marca mais forte e promissora daquela literatura, a "politização da análise da pobreza" (Machado da Silva, 1993). O caminho escolhido torna mais difícil o enfrentamento dos dilemas que permeiam a tradição da análise política brasileira.
Um primeiro dilema diz respeito a uma reflexão que se faz por comparação a modelos de proteção social, de cidadania e de Estado típicos do Welfare State. Na medida em que apenas marginalmente se discute a forma do Estado e a constituição (ou não) da esfera pública no Brasil, acabar-se-ia, no limite, chegando a uma transposição de categorias e conceitos sem vigência histórica (Machado da Silva, 1993; Cohn, 1992a). Ou seja, à produção de “idéias fora de lugar". A retomada da discussão sobre a especificidade do Estado na América Latina e, portanto, do caráter particular de suas relações com a sociedade civil impõe-se como uma tarefa teórica urgente nesses tempos de crise do poder regulatório do Estado e de aparente regresso, nas relações sociais, a uma situação de "estado natural no sentido hobbesiano" (Santos, 1993).

Um segundo dilema consiste no abandono da problemática convivência entre a análise econômica e a análise política (Machado da Silva, 1993), tida como equivocada ou irrelevante face à autonomização do mundo da política. Trata-se de um dilema porque nos deixa sem um instrumento metodológico para entender as clivagens produzidas na sociedade civil, as diferenciações sociais dentro dos grupos, as dificuldades de constituição dos sujeitos na esfera do político. Se este não é um problema para aqueles que, weberianamente, pensam a realidade social como intrinsecamente fragmentada e descontínua (Bodstein, 1992), o é para outros preocupados com a formulação de políticas e estratégias. A perda da dimensão relacional entre economia e política inviabiliza a análise das relações de força ao obliterar o momento econômico-corporativo que define a factibilidade das ideologias e dos projetos políticos (Gramsci, 1968).

Esses dilemas não passaram, porém, desapercebidos. Labra (1988), comentando sobre as análises das políticas de saúde, observa que o entendimento de qualquer política pública necessariamente deveria remeter, em última instância, ao caráter das relações Estado-sociedade e, portanto, às questões específicas da natureza de classe do Estado capitalista dependente, do tipo de regime político vigente, do pacto de domínio que o sustenta e da composição das forças que imprimiram certa direcionalidade à política em questão. Aponta 
ainda outra questão relevante: a evolução institucional do Estado deve considerar os condicionamentos impostos pelo padrão histórico de desenvolvimento econômico no país.

Parece-nos que o ponto de inflexão da produção acadêmica está claramente referido ao segundo dilema acima apontado. Alguns esforços para enfrentá-lo vêm sendo ensaiados. Cabe mencionar aqui, entre os defensores de uma renovação crítica do aparentemente superado "paradigma dos movimentos sociais", a proposta de reconceitualização da cidadania no Brasil, distinguindo-a, em função de diferentes condições de reprodução social de camadas ou de grupos sociais, em "cidadania de vigilância" e "cidadania de escassez" (Valla, 1987). São conceitos “operacionais", de conteúdo empírico, construídos para retratar uma situação de estratificação sócio-política de caráter fortemente excludente, e que sinalizam para a dificuldade da constituição de uma esfera pública no Brasil.

\section{Dilemas da Prática Política}

A reconceitualização da cidadania, tal como proposta, traz também, como aponta Cohn (1992b), uma contribuição para pensar a natureza ou o perfil das políticas públicas no país, na medida em que estas assumem, para a grande maioria da população trabalhadora, o caráter de políticas compensatórias, não-preventivas, redistributivas, focais e não-universais.

E aqui gostaríamos de chamar atenção para os novos modos de tematizar movimentos sociais e saúde. A preocupação com a constituição e ação dos sujeitos coletivos frente à necessidade de instaurar um padrão de proteção social de cunho universalista não pode mais, a nosso ver, desconsiderar a desinstitucionalização dos padrões sociais - ou o "estado de natureza no sentido hobbesiano" em que parece mergulhar a sociedade brasileira.

Para Santos (1993: 109)

\section{"Existe no Brasil um estado de natureza em sentido hobbesiano, ou seja, aquele no qual o conflito é generalizado e a regra constitucional vigente é cada qual administrar seus próprios problemas, sem apelo a instâncias superiores, aceitas pelas partes belierantes".}

O que está em crise é o chamado poder instituinte do Estado, quer dizer, das formas e processos de institucionalização da cidadania, lastreados em normas e leis. Reorganizados a partir da democratização política, tais formas e processos não lograram ter, no Brasil após a ditadura militar, plena vigência. Foram, pelo contrário, ao longo dos anos 80 e início dos 90 , esvaziados progressivamente em seu conteúdo. A onda neoliberal que tomou corpo no governo Collor afetou profundamente a capacidade do Estado de regular os conflitos sociais na perspectiva da cidadanizaçã; tornou a vigência ilimitada das leis do mercado o traço marcante do ingresso do país na "modernidade"; e configurou para a política pública na área social um papel compensatório e de intervenção focalizada. Como resultado desse processo, a democratização política assumiu uma feição dominantemente formal.

O impacto da crise do poder instituinte do Estado sobre a possibilidade da constituição dos sujeitos é devastador. Se os sujeitos coletivos se constituem na esfera do político, envolvendo necessariamente as formas e processos de institucionalização da cidadania, entre os quais o da representação, a ausência ou pouca efetividade dessa esfera afeta principalmente aqueles grupos mais pobres e mais desorganizados, com poucas chances de administrar individualmente os problemas sociais de sua existência.

A análise política encontra-se, aqui, com a análise econômica: as dificuldades de constituição dos sujeitos na esfera do político estão, em parte, relacionadas à estrutura social do capitalismo em nosso país. Mais especificamente, à segmentação social existente nas classes trabalhadoras, um processo que se aprofundou ao longo dos anos 80 para cá, dada a perda de dinamismo da acumulação de capital e a precarização do mercado de trabalho a ela associada. É possível, deste modo, discriminar as classes trabalhadoras em nosso país em três grandes grupos: os trabalhadores do setor "moderno e dinâmico" da economia, um grupo cada vez mais reduzido e regionalmente concentrado; a massa de assalariados "com carteria" que, ainda majoritário, diminui a cada ano; e a massa de trabalhadores urbanos e rurais do "setor informal”. Estamos diante de um sistema de 
estratificação social que afeta incisivamente a capacidade de expressão política das classes trabalhadoras (Andrade, 1982).

\section{A PARTICIPACCÃO SOCIAL NO SISTEMA PÚB̉LICO DE SAÚDE}

Sem esta análise, sem descortinar estes processos políticos, sociais e econômicos, parecenos improvável dar conta, no âmbito da política social de saúde, do fenômeno da universalização excludente (Favaret-Filho \& Oliveira, 1989).

Sabe-se que a implantação de um sistema público de saúde no Brasil, envolvendo os prestadores de serviços de entidades estatais, filantrópicas e privadas contratadas, acarretou, devido à crise fiscal do Estado e à deterioração da qualidade do atendimento, o fortalecimento do setor privado autônomo. Diferenciou-se, em conseqüência, a demanda social por saúde, excluindo-se da atenção do sistema público as camadas mais bem pagas do proletariado urbano.

Para simplificar os termos de uma questão razoavelmente complexa, considere-se que as políticas sociais, em especial na área da saúde, expandiram-se fundamentalmente com base na capacidade contributiva dos trabalhadores. Mas tal capacidade foi a persiste sendo desigual. As camadas mais bem pagas, ligadas aos setores "dinâmicos" e "modernos" da economia, sustentaram os fundos indispensáveis para o atendimento das camadas mais mal remuneradas dos trabalhadores, tanto nas cidades como no campo. E aquelas camadas mais bem pagas estabeleceram, historicamente, um relação "adversa" com o sistema público de saúde: passaram a privilegiar e utilizar os convênios com empresas médicas, descrendo de qualquer capacidade dos serviços públicos de contemplar suas necessidades.

Para esta camada social, o mercado passou a ter um papel central na provisão de diferentes tipos de seguro de saúde, papel intermediado pelos acordos sindicais com os empregadores. O seguro de saúde "com cobertura sindical" é, segundo Navarro (1993), um dos mecanismos que promovem divisões na classe trabalhadora.
A estratificação do proletariado no Brasil contemporâneo não deu lugar a divisões políticas internas entre diferentes camadas e grupos. Em parte isto provavelmente se deve às condições de exploração da força de trabalho vigentes, mas também, em grande medida, devido à ausência de uma tradição de assimilação empresarial do operariado, ou seja, à atitude historicamente autoritária e reacionária do patronato (Andrade, 1982).

O conjunto dessas colocações permite repensar a questão do "controle social" ou da participação dos usuários no planejamento, avaliação e fiscalização das ações em curso no sistema público de saúde, destacando as implicações políticas da chamada universalização excludente. A questão que se coloca é: na medida em que a participação social dos usuários no sistema público de saúde assume a forma jurídico-institucional dos conselhos, não estariam representados, tendencialmente (sobretudo no nível municipal), os segmentos mais pobres e, também, menos organizados da classe trabalhadora, os quais têm sido, historicamente, alvo de políticas clientelísticas?

\section{RESUMO}

STOTZ, E. N. Movimentos Sociais e Saúde: Notas para uma Discussão. Cad. Saúde Públ. Rio de Janeiro, 10 (2): 264-268, abr/jun, 1994. $\mathrm{Na}$ forma de anotações para intervir no debate sobre a contribuição dos cientistas sociais na construção do campo da saúde, o presente texto aborda a problemática das dificuldades e perspectivas da incorporação de uma temática específica - a dos movimentos sociais. Aponta-se, na crítica ao "politicismo" da tradição da análise política brasileira, o problema da diminuição do poder reflexivo sobre uma questão teórica e politicamente relevante, a saber, a da constituição dos sujeitos coletivos na conjuntura, e procura-se indicar tentativas de superação desse impasse.

Palavras-Chave: Movimentos Sociais; Saúde Coletiva; Ciências Sociais; Análise Política; Participação Social 


\section{REFERÊNCIAS BIBLIOGRÁFICAS}

ANDRADE, R.C., 1982. Política social e normalização institucional no Brasil. In: América Latina: Novas Estratégias de Dominação (L. Maira, J. H. Souza, R. C. Andrade, J. C. Portantiero \& X. Barraza, coord.), pp. 87-114, Petrópolis: Vozes/São Paulo: Cedec.

BODSTEIN, R. C., 1992. Ciências Sociais e Saúde Coletiva: novas questões, novas abordagens. Cadernos de Saúde Pública, 8: 140-149.

COHN, A., 1992a. Conhecimento e prática em saúde coletiva: o desafio permanente. Saúde e Sociedade, 1: 97-109. , 1992b. Debatendo a questão das políticas de saúde e movimentos e atores sociais. In: Pesquisa Social em Saúde (A. W. P. Spínola, E. W. C. Sá, M. F. Westphal, R. C. F. Adorno \& F. Zioni, coords.), pp. 113-116, São Paulo: Cortez.

COSTA, N. R., 1989. Transição e movimentos sociais: contribuição ao debate da Reforma Sanitária. In: Demandas Populares, Políticas Públicas e Saúde (N. R. Costa, M. C. S. Minayo, L. L. Ramos \& E. N. Stotz, orgs.), vol. I (Ciências Sociais e Saúde Coletiva), pp. 45-65, Petrópolis: Vozes/Rio de Janeiro: Abrasco.

FAVARET-FILHO, P. \& OLIVEIRA, P. J., 1989. A Universalização Excludente (Reflexões sobre as Tendências do Sistema de Saúde). Rio de Janeiro: Instituto de Economia Industrial/Universidade Federal do Rio de Janeiro. (Série do IEI/UFRJ, Textos para Discussão, 216). (Mimeo.)
FLEURY, S. (Org.), 1992. Saúde Coletiva? Questionando a Onipotência do Social. Rio de Janeiro: Relume-Dumará.

GRAMSCI, A., 1968. Maquiavel, a Política e o Estado Moderno. Rio de Janeiro: Civilização Brasileira.

LABRA, M. E., 1988. Proposições para o estudo da relação entre política, burocracia e administração no setor saúde brasileiro. Cadernos de Saúde Pública, 4: 33-48.

MACHADO DA SILVA, L. A., 1993. Desdobramentos do campo temático dos movimentos sociais. Cadernos do CEAS, 145: 39-49.

MACHADO DA SILVA, L. A. \& RIBEIRO, A. C. T., 1985. Paradigma, e movimentos sociais: por onde andam nossas idéias? In: Ciência Sociais Hoje (Anuário de Antropologia, Política e Sociologia), pp. 318-336, São Paulo: Cortez/ANPOCS.

NAVARRO, V., 1993. Produção e estado de bemestar. O contexto político das reformas. Lua Nova, 28/29: 157-199.

SANTOS, W. G., 1993. Mitologias institucionais brasileiras: do leviatã paralítico ao estado de natureza. Estudos Avançados, 17: 101-116.

SOUZA, L. R., 1990. Movimento de saúde: dificuldades à sua apreensão. Saúde em Debate, 29: 48-51.

VALLA, V. V., 1987. Movimentos Sociais, Saúdee a Questão da Verba Pública. Petrópolis: $\mathrm{CDDH}$.

VALLA, V.V. \& STOTZ,E. N., 1989.Participação Popular e Saúde. Rio de Janeiro: Cepel/ Petrópolis: $\mathrm{CDDH}$. 